\section{Eighth Oxford Conference on Microscopy of Semiconducting Materials Set for 1993}

\section{Abstracts Being Accepted}

The eighth biennial conference on $\mathrm{Mi}$ croscopy of Semiconducting Materials, to be held on April 5-8, 1993 at Oxford University, will focus on advances in transmission and scanning electron microscopy of the structural and electrical properties of semiconductors. Developments in the use of other micro-characterization techniques such as x-ray topography, scanning tunneling microscopy, atom probe microanalysis and ion backscattering spectrometry will also be featured. The conference will cover a wide range of elemental and compound semiconductors.

Subject areas include the characterization of as-grown semiconductors in both bulk and thin film forms, the study of lattice defect and impurity behavior and the investigation of the effects of semiconductor processing treatments. Special conference sessions will concentrate on recent advances in high resolution electron $\mathrm{mi}$ - croscopy work, the nature of epitaxial layers, quantum wells and superlattices, the properties of dislocations, the characteristics of metal-semiconductor contacts and silicides, the effects of device processing treatments and the exploitation of advanced scanning techniques (SEM-CL, SEM-EBIC, STM, AFM, etc.).

The provisional list of invited speakers includes J.L. Batstone (IBM, Yorktown Heights), "In-situ TEM Studies of the Crystallization of Amorphous Si: the Role of Silicides"; D. Bimberg (Technical University of Berlin), "Cathodoluminescence Imaging of Quantum Wells and Wires"; J. Brown (Sematech, Austin), "Microscopy of ULSI Structures"; F. Glas (CNET, Bagneux), "Composition Modulations and Clustering in III-V Alloys"; M.A.G. Halliwell (Philips, Almelo), "The Role of XRD in the Characterization of Semiconductor Heteroepitaxial Structures"; C.J. Humphreys (University of Cambridge), "Electron Microscope Investigations of Heteroepitaxial Materials"; A.G. Norman (Imperial College, London), "Nature and Origin of Atomic Ordering in III-V Alloys"; A. Ourmazd (AT\&T Bell Labs, Holmdel) "Quanti- tative HRTEM of Semiconductors"; J.B. Pethica (University of Oxford), "STM of Semiconductor Surfaces"; J.M. Poate (AT\&T Bell Labs, Murray Hill), "Defect Engineering in Semiconductors"; K. Sumino (Tohoku University, Sendai), "Dislocation Dynamics in Semiconductors."

The conference proceedings will be published and contributed papers are requested in all the areas outlined above. The abstract deadline is December 1, 1992. Further information about abstract submission and registration can be obtained from: The Administrator, Royal Microscopical Society, 37/38 St. Clements, Oxford OX4 1AJ, U.K. (44-865-248768; fax 44-865791237).

The conference is organized under the auspices of the Royal Microscopical Society and the U.K. Institute of Physics, and is endorsed by the Materials Research Society. The conference co-chairs are A.G. Cullis, DRA Malvern, U.K. (44-684-894509; fax 44-684-894540) and A.E. Staton Bevan, Imperial College, London, U.K. (44-71-5895111, ext. 5925; fax 44-71-584-3194).

\begin{tabular}{|lr|}
\hline \multicolumn{2}{|c|}{ Advertisers in this issue: } \\
\hline Bomem & 9 \\
\hline Burleigh Instruments & 35 \\
\hline Depths of the Earth & 38 \\
\hline Drexel University & 38 \\
\hline High Temperature Engineering & 17 \\
\hline High Voltage & inside front cover \\
\hline Engineering & inside back cover \\
\hline Huntington & 26 \\
\hline Laboratories & 14 \\
\hline Kurt J. Lesker & 12 \\
\hline Lake Shore & 6 \\
\hline Micro-Optics & 4 \\
\hline MKS Instruments & 13 \\
\hline National Electrostatics & 3 \\
\hline Park Scientific & 11 \\
\hline Perkin Elmer & 10 \\
\hline Pure Tech Inc. & 48 \\
\hline Rigaku & 44 \\
\hline Siemens & 26 \\
\hline VCH Publishers & 31 \\
\hline VCH Publishers & \\
\hline Virginia Semiconductors & \\
\hline Voltaix & \\
\hline Carl Zeiss & baver \\
\hline For free information about the products and \\
services offered in this issue, fill out and \\
mail the Reader Service Card, or FAX it to \\
(312) 922-3165. \\
\hline
\end{tabular}

\title{
CLASSIFIED
}

\section{Positions Available}

\section{RESEARCH SCIENTIST \\ (ELECTRON MICROSCOPY) \\ University of Illinois \\ at Urbana-Champaign \\ Materials Research Laboratory}

The Center for Microanalysis of Materials in the Materials Research Laboratory of the University of Illinois at Urbana-Champaign is a major facility for the characterization of materials using electron microscopy, microchemistry and surface analysis. The Center is used by researchers in a wide range of scientific fields related to materials science. It operates and develops many instruments which are used by over 300 researchers each year. The Center has an open position for an electron microscopist, specializing in TEM.

The staff of the Center have a broad range of responsibilities. They work with users on their research, train users, maintain the instruments, and have the opportunity to develop new techniques and instrumentation.

We anticipate that the person's time will be divided more or less equally between maintenance and the training and research functions. Applicants should have an advanced degree or several years of experience in an electron microscopy laboratory. They should have a good background in transmission electron microscopy and microanalysis. To handle the maintenance responsibilities, applicants should have prior experience with vacuum systems and in digital and analog electronics.

This is a nonteaching, $100 \%$ time, regular appointment with standard university benefits. Salary will be commensurate with education and experience. The position is available in the Fall of 1992. In order to ensure full consideration, applications must be received by October 31, 1992. Please send letter of application, resume and three letters of reference to: Prof. H.K. Birnbaum, c/o Donna Jacobs, University of Illinois, Materials Research Laboratory, 104 South Goodwin Avenue, Urbana, Illinois 61801, phone (217) 244-2944. 